\title{
From domestic experience of organizational, cultural, polytechnic educational space formation as a strategic direction of education modernization
}

\author{
Sergei Z. Zanayev ${ }^{1, *}$ and Aleksandra E. Ushnitskaya ${ }^{2}$ \\ ${ }^{1}$ ISED RAE, Laboratory of History of Pedagogy and Education, 105062, Moscow, Russia \\ ${ }^{2} \mathrm{NEFU}$, Methodological Training Center of the Pedagogical Institute, Yakutsk, Russia
}

\begin{abstract}
The organizational and cultural aspects of the history of the development of general polytechnic education representing strategically important direction of modernization of education in the contemporary information age are considered in the article.
\end{abstract}

An interest to the organizational culture research has been growing, beginning approximately from the second half of the eighties of the $20^{\text {th }}$ century.

A significant contribution to the development of the theory of organizational culture was made by a number of Russian and foreign scholars. Their works revealed the essence and content of organizational culture and analyzed its components.

The analysis of organizational culture development allows us to apply this approach as the basis of organizational and management activity of school education improving. All educational institutions also have their own culture, like any other organizations with their own history. In the most general form it is a set of basic hypotheses and beliefs, formation and development of which, that is often implicit and almost unconscious, begins simultaneously with the emergence of institutions, and currently it is taken for granted.

In the context of global challenges of the $21^{\text {st }}$ century the education system is the most important social institution where the fundamental needs of society in formation and development of a personality, who is adequate to the social realities of a constantly changing world, is realized. However, the formation of organizational cultures functioning today in educational systems of Russia actively had been taking place in the 20-50s of the last century, when overall polytechnic and labor education had great importance in the process of culture organization and building, education, industrial and economic development of the country.

In this period achievements in the organizational culture obtained in the Central Institute of Labor (CIT) in Moscow founded by A. K. Gastev became widely known. His methods became well-known abroad and are recognized in the USA, Great Britain, France and many other countries. of methods of scientific labor organization (NOT). Methods of the natural sciences, sociology, psychology, pedagogy, physiology were widely used in the research of CIT (Central Institute of
Labor). A. K. Gastev made a great contribution into development of Cybernetics and General systems theory. His methods and developments were widely accepted by many countries, and they are studied in the USA, England, France and other countries.

A. K. Gastev had great experience of working at the Ford factories and he was in personal correspondence with him. Thinking of how the German workers have organized work culture, he came to conclusion that our workers should be taught to such culture and it would be better to start from childhood. The formation of work culture according to the techniques of CIT is not just "book learning", but progressive and systematic education of habits and skills through training and its consolidation. A.K. Gastev considered that the Russian worker need education of performing culture: the ability to obey the exact observance of duty, technical discipline, regardless of personal attitudes. Art and culture in the organization of collective work, according to Gastev, is in the ability to override ones personal goals to the common tasks, to the ability to accurate and appropriate execution of commands and orders.

It is interesting that A.K. Gastev has supposed that such training is necessary not just to managers and employees but to all the country citizens who should go through the NOT (Scientific Labor Organization) school. These methods and approaches application in labor culture education, in his opinion, should be started when a child is 2 years old, not 14 . At the same time Gastev considered that a new culture could not be created by training obedience and diligence only that made a person the "small screw" of the industrial system. He believed that industrial and economic development of Russia was closely connected and inseparable from cultural growth of society.

In the 20-30s the ideas and aims of A.K. Gastev were extensively applied and developed by S.T. Shatsky, A.S. Makarenko who achieved amazing results in all areas of

\footnotetext{
*Corresponding author: zanaev@yandex.ru
} 
organizational culture in the institutions they have created.

S.T. Shatsky, A.S. Makarenko demonstrated to others the contagious models of organizational culture of General Polytechnic education by their own examples. There was achieved remarkable success in pedagogical, cultural, organizational, social, training and production activities in both institutions that had passed a thorny way of formation.

The First Experimental Station schools activity of Public Commissariat of Education (Narkompros) by S. Shatsky brought a lot of new, interesting and useful to the local culture and life organization of surrounding locations.

A necessary condition for successful school activity, according to S. Shatsky, was its "interaction with the environment, participation in the life construction" [1]. In studying and working process in such evolutionary system students gained diversified knowledge, abilities, skills, passed extensive agricultural polytechnic training. School stations had considerable, socially useful and significant work on improvement and gardening of villages, dissemination of pedagogical, polytechnic, agricultural knowledge among the population. Outstanding internationally recognized achievements of the First pilot station demonstrated that the sociable activity of school positively contributes to the overall region development, thereby it fulfilled an important social, economic, organizational and cultural function.

In the organization of educational work of the First experimental station S.T. Shatsky proceeded from the principle of education and life unity of children. He stated that in the educational process there might be used such teaching methods which gave the opportunity to be based on children's life experience. The prominent pedagogue, developing the connection between school and life, considered the combination of physical labor, games, mental activity and social work, "filled with meaning for the children" to be important. S.T. Shatsky was staunch supporter of practicing the projects methods as a way of organizing the cognitive activity of students and formation of their social experience in a Soviet school [1].

In schools of the First Experimental Station students studied the life of rural inhabitants, development of local crafts, weaving, in particular. Complex methods of teaching were used in this direction research.

The pedagogue suggested to use widely such methods of academic work of students as independent observation, fulfillment of work tasks, participation in productive and socially beneficial work, execution of contractual production orders in school practice.

The principle of connection of theory with practice was realized in studying process of Experimental Station schools. The work in this case was organized as an essential condition for the personality progress combining various kinds of developmental activities, aesthetic, organizational, cultural, intellectual, gameplaying. In schools of the Experimental Station the labor training was well organized: there were working and experimental areas, horticulture, gardening, floriculture production clubs, different sections.
In 1920 s in theoretical works and in the activities led by S.T. Shatsky at the First Experimental Station of Narkompros great attention was paid to the development of students' intention to research, to connection of their life experiences from family, children group, communicating with adults, with a system of knowledge accumulated by mankind, the study of the economy, culture and lifestyle influence on the development of learners, application of various forms of student participation in the restructuring of the life conditions, etc.

S. T. Shatsky stated that the goals of education reflected the needs of the state and society, defined by time and space, but at the same time they depended on individual and age peculiarities of a child. At each stage of progress the teacher should create the most favorable atmosphere for the full potential of the child, his spiritual and physical strength. S. T. Shatsky sought to create conditions for children creative activity. According to the scientist, the school must teach pupils to combine efforts to achieve common goals. Special attention was paid to children's self-control as an important instrument in the regulation of child life. Favorable psychological atmosphere in a group was achieved through the cooperation of teachers and students, their trust attitude to each other, staff openness to growth, innovation, ability to overcome inevitable difficulties. The school reform, according to S. T. Shatsky, should begin with teachers' training reform. They should be able to reflect, to analyze their own achievements and mistakes, and basing on this analysis move forward in their work.

Interest of domestic pedagogics was in the experience of realizing of school and life connection in the process of organizational and cultural, public and social institutions work of A.S. Makarenko institutions also successfully worked this period [2].

The research of S.T. Shatsky, A.S. Makarenko legacy showed that in the process of different types of educational, training and production activities they tried to find the best solutions from different life situations and difficulties together with their colleagues and students. They created and founded together with students and staff the interesting and perspective elements of organizational culture: traditions, customs, habits, rules, taboos, ideals and values, a clear fulfillment of which led ultimately to the outstanding success in the activities of these institutions. All-around polytechnic and labor education was realized during this process.

Herewith it is important that S.T. Shatsky and A.S. Makarenko together with colleagues and students got versatile knowledge, skills during the different types of organization of educational production activity. For example, when they were busy with agricultural production along with studies, they created suitable psychological and emotional training and the environment that assisted them in mastering enthusiastically all the stages of this difficult direction, during which they received thorough polytechnic education, they had the labor training, education and civil formation.

These institutions groups promoted and distributed polytechnic knowledge using modern methods of 
agricultural production among the population while solving various educational tasks. The results and products of their hard work were interesting to the inhabitants who were interested in techniques and methods of agriculture, cattle breeding, processing of agricultural products. For example, there was organized free distribution of pure-bred pigs, consultations on their care and keeping, constant receive and grain grinding from the peasants in the colony of A.S. Makarenko. The students of both institutions regularly performed plays and performances where S.T. Shatsky participated in together with students and staff. The population of the surrounding villages actively attended these theatrical performances and discussed them. In both institutions there were bands, which were often invited to conduct various, massive social and cultural events.

Of great social importance was the solution making accepted by A.S. Makarenko collective of the children concerning the fusion with the colony in Kuryaj. They wanted it not only because of carrying out an important state task but to help the children who turned out to be in complex, dramatic life situations. To solve this difficult problem, they largely contributed into the fact that they acted as a single, clear organizational and cultural wellcoordinated, cooperative team, united with a general interest and socially important goal.

Further, in the commune named after F. E. Dzerzhinskii, A.S. Makarenko also with the help of appropriate specialist, along with a team went through all the initial stages of development of various kinds of technological processes of production of various technically complex products. In this process they not only gained valuable experience and extensive technical knowledge and skills, but also passed their organizational and cultural, employment, creative, production formation and hardening, as a single cohesive team.

Joint research had the character of unifying principle - joint research of optimal ways, methods and means, solutions and execution, encountered different organizational, production, technological and design problems. Later A. S. Makarenko leaning closely and creatively interacting with the main team of the commune, began successfully mastering the production of technically and technologically more sophisticated products, which were in great demand.

In pedagogical terms an important meaning was that at every stages of formation, in the solution process and perform various emerging educational, industrial, life situations and difficulties, one group of institutions S. T. Shatsky, A. S. Makarenko received valuable diverse experience of educational social-psychological, organizational, cultural, educational cooperation and collaboration.

Subsequently as a leading teacher-scholar, doing analysis, generalization and dissemination of its rich experience in educational, public and social, organizational and cultural, educational and industrial activity of A. S. Makarenko conducted a comparative study of the general state of domestic education. Meaningful assessment in the prevailing attitude of youth of those years on the example of the vocational preferences of its students is the statement presented to them in lecture, which he delivered on 10 January 1938. He noted that "in those years was a general passion for technology, technical education, and all my students wanted to be engineers" [3].

Methods, receptions, techniques, means and ways of achieving these preferences among the youth of those years are presented objective value in general, and need their reinterpretation and application in the education and upbringing of the younger generations in the modern information age.

Describing the period 1920-30-s we should show the total organizational and cultural policy, against which the development of scholars and practitioners of the problems of polytechnic education.

In those years all over the country at a rapid and intensive rate the following events were taking place. The number of schools, village reading rooms, extensive network of various libraries, educational institutions, universities with the training available to adults and children was increasing. The new theatres, museums, amateur clubs, cinemas were being opened. The great significance was given to the cinematography, as a means of mass cultural-educational, educational influence on the younger generation and the population of the country. The organization of the whole system of culture has been focused on the formation of values and ideals for the creation of a positive image of workers, rural workers, technical intelligentsia, military.

The product of film art, television, radio, print media, different genres of literature, song, art and culture of the peoples of the Soviet Union, the activities of various public organizations were aimed at increasing the prestige and importance of labor for the Motherland in any field of the national economy, on the formation of the young generation of the relevant ideals and values. For example, in the museums of the USSR were shown paintings, glorifying the pathos, the romance and the poetics of the labor of ordinary workers, farmers, factory workers, military personnel.

One of the most famous and recognizable works of art and cultural, monumental art of these years is the famous monument of Vera Mukhina "The Worker and the Collective Farm Girl" - an internationally recognized masterpiece of socialist realism, which became the symbol of Soviet power.

A series of state labor awards of the USSR, approved during this period are the most important specific direction of organizational, cultural and leadership policy of the country. There were established 16 prizes in all fields of science, culture and art, the inventors for achievements in the field of military sciences. In 19404 prizes for literature were adopted. All of these awards were awarded annually. Procedures for the award was widely reported in the press, radio, in the labor collectives, thus they carried a great universal upbringing function.

In the organizational and cultural construction and development of the national system of general polytechnic education the extensive interdepartmental, cross-cultural approach was involved. The general idea of the development of education, polytechnic education, 
labor, patriotic education and formation of the personality qualities of the younger generations, as future workers and defenders of the Motherland, in the spirit of friendship and mutual understanding between the nations of the country, was the "core" guiding, unifying and consolidating. These features of the national system of education are objective potential value and applicable in the development of modern education, technological polytechnic training of the younger generations in the modern information age.

It is characteristic that in this important state-level task not only the school establishments were involved, but also a various extracurricular and cultural institutions, museums, clubs in a residence, the houses of pioneers and technical creativity, houses of culture at plants, factories, agricultural enterprises, village library and reading rooms in rural settlements, party and labor unions and socio-cultural associations, different media (mass media), etc. The activities of these various agencies has been focused on diverse of the culturalpublic work with the whole population, in particular for the organization of sections of circles of technical creativity and artistic associations, mostly free and therefore accessible to all children and adolescents. In these institutions the wage-rates of teachers-organizers were allocated for work with students, logistical issues were solved together, massive contests, competitions, meetings were held systematically, etc.

Komsomol (the All-Union Leninist Young Communist League of the Soviet Union) youth movement took an active organizational, cultural and educational participation in the multilateral activities. In the resolutions of the IX Congress of the All-Union Leninist Young Communist League of the Soviet Union (26 January 1931), a number of decisions to improve universal education and literacy for children's cultural upsurge of children masses and to improve the material and domestic status of children have been adopted.

Among the tasks the wide development of seven-year schools, the organization of polytechnic education, the increasing of national defense were considered. The resolutions noted the need to strengthen the "militarypolitical upbringing of children and widespread deployment among military and sports work. The adoption of patronage over air force by the Komsomol imposes on the pioneer organization responsibilities of broadest propaganda of the masses of children and adults the ideas and specific tasks of patronage, assistance to the Komsomol in their implementation, of acquaintance of children with aerotechnics and dissemination of aviation modeling and gliding in the pioneer pack, schools and clubs ..." [4]

This period in the history of the state and education development is associated with the emergence and organization of mass voluntary defense societies (Society of Friends of Air Fleet, Volunteer Society for Cooperation with the Army, Aviation, and Fleet, Society for Support of the Defense, Aviation and Chemical Industries, Central Aeroclub of the USSR).

The roots of today's success in aviation, rocketry and cosmonautics of the country have their origin in that time. This shows the close relationship and historical continuity of the past, present and future development of the organizational culture of general polytechnic education and the state.

Of great importance in improving the health of people had the initiative of the Komsomol which in 1931 was introduced the all-Union sports complex Ready for the Labor and Defense of the USSR (GTO), which received mass recognition and engulfed the population, aged between 10 to 60 . The author and creator of the sport complex was Ivan T. Osipov. In 1932 the complex was supplemented by a 2nd stage, in 1934 - by the "Be Ready for the Labor and Defense" stage (BGTO).

The requirements of industrial and economic development, the improvement and reconstruction of various sectors of the economy, the broad introduction and dissemination of new technology, the widespread development of mechanization is strongly dictated the necessity of raising the general cultural level and special technical training of personnel. The various organizational and cultural events for the transformation of the system and content of school education, mass polytechnic education of the younger generations were aimed at solving these problems.

At the XVI Congress of the Communist Party of the Soviet Union (Bolsheviks) in 1930 the tasks of reconstruction of all sectors of national economy, based on modern technology, the strengthening of economic independence and the improvement of country's defense were set. For the successful solution of the tasks set by the Congress the following was required: the organization and improvement of infrastructure for mass polytechnic education of the younger generations and adults, for mastering new production and technical knowledge and skills by workers, for creation of engineering and technical intelligentsia.

In the 1930-s the strong support was received from an interesting initiative on the organization of the city and country camps, children's railways and shipping lines, and stations for young tourists and technicians, naturalists, etc.

Considerable attention was paid to the organization of mass extracurricular activities of children and adolescents in implementation of the objectives of education and training. In January 1935 in the building of the State Polytechnic the permanent exhibition of children's technical creativity Museum was opened, and the special pavilion of young naturalists at the All-Union Agricultural Exhibition in Moscow was built.

In the promotion and development of the polytechnic orientation of education of the population the trade unions, youth associations were actively participated. The agitation events for building and raising funds for the first machine-tractor stations (MTS) were organized by the Komsomol movement, the Subbotniks (Saturday day of unpaid work) were carried out, the special "Komsomolsk's hectares" were seeded, the training of machine operators was carried out. The slogan "Komsomol - go to tractor!" nominated by the Central Committee of the Komsomol was one of the most common and popular in the village. The mass involvement of future conscripts contributed to more rapid development of their internal structure and the 
basic principles of combat vehicles (tanks, selfpropelled, tractors, etc.), and to the acquisition of general skills driving them.

The organization of technical creativity circles for all children in relation to pedagogy and polytechnic education was valuable. Pioneers at these institutions also participated in "the public useful work on landscaping of streets and yards in which they lived, became acquainted with the work of urban enterprises. This approach partially contributed to the expansion of their polytechnic range of view". [5]

The revitalization of the production-technical propaganda in the country contributed to the release of several guidance documents of the party and government. For example, on May 25, 1931, the Central Committee of the Communist Party of the Soviet Union (Bolsheviks) adopted a resolution [6] which noted the need "to ensure the publication in millions of copies of cheap mass popular technical literature and publiclyavailable textbooks on technology, both in the general framework of technology and industry". The implementation of this decision was recorded in the following party decree, dated December 29, 1931, in which emphatically there was a need "to immediately deploy the work to create massive well-published technical books for young people. Pioneering book must mobilize mass pioneers as a leading children's asset to perform tasks on the involvement of children in public life, in polytechnic school".

In the prewar years the topical issues for a school were staged for the pedagogical science. Among them: the increasing of student achievement and overcoming of grade repetition, the conscious discipline skills upbringing and the preparation of pupils for future practical work, including for military service.

The Great Patriotic War was a severe test and at the same time showed tremendous preventive, strategic importance of the national system of education, polytechnic training, pre-conscription training of youth, as well as the civil, international and patriotic upbringing of the population. The organization of the national system of the general polytechnic education in the difficult war years had proven the extremely vital importance and necessity in the direct protection and defense, strengthening and construction of the state. V. P. Potemkin, the first president of the Russian Soviet Federative Socialist Republic, in his report in August 1945 noted: "we are all proudly aware that the valiant defenders of the Motherland, the winners of German fascism was the alumni of the Soviet school. The Soviet school defeated the fascist school; the Soviet teacher defeated the German teacher-fascist" [7].

There is no doubt that the broadest organizationalcultural, comprehensive, polytechnic, military-applied orientation of mass education and sensitization of the population, including children of school age was strategically important factors of victory in the Great Patriotic War.
According to S. V. Ivanova, "now, more than ever, it became clear that only those pedagogical ideas and initiatives have the right to existence and implementation, which have passed a detailed theoretical expertise and have been evaluated as continuity from the historical and pedagogical point of view" [8].

It is by no means certain that the domestic experience of organizational and cultural development of general polytechnic education was a long test of time and in the difficult war years proved its urgency and strategic vital necessity in the matter of direct protection and post-war revival of the state.

In modern conditions highest state authorities of the Russian Federation have taken a long-term strategic course for modernization of the military-industrial complex, for development of the domestic scientific and industrial base by using its own technical capacity, for implementation of import substitution of foreign goods by domestic. Without this it is impossible not only the dynamic social and economic development of the country, but also the achievement of national security of Russia. In these circumstances, the study of the domestic experience of organizational and cultural aspects of the formation of universal polytechnic education space becomes actual and strategically important in the modernization of education in the information age.

\section{References}

1. S. T. Shatskii, Pedagogy, 2, 416 (1980)

2. S. S. Neva, DFP, 6 (27), 36-52 (2015)

3. A. S. Makarenko's methods of education, Pedagogy, 8, 16-27 (2007)

4. IX All-Union Congress of the Komsomol (Young guard, Moscow, 1931)

5. M. V. Boguslavskii, Children's movement in Russia: between the past and the future (Scientific Book, Tver, 2007)

6. The decree of the Central Committee of the CPSU (b) from may 25 (1931), "About the Production and technical propaganda"

7. V. P. Potemkin, Articles and speeches on questions of public education (Publishing house of the RSFSR, Moscow-Leningrad, 1947)

8. Teaching science: the Genesis and development forecasts: Sat. scientific. Tr. International scientifictheoretical conference on 28-29 may 2014. (FSSI and media type RAO, Moscow, 2014)

9. S. Z. Sanaev, All my students wanted to be engineers (R, 2014)

10. A. E. Osniecka, PE, 2 (41), 83-90 (2012). 